\title{
MELANOCITOMA PERIVULVAR CONGÊNITO EM BOVINO
}

\author{
Juliane Teramachi Trevizan ${ }^{1}$ \\ Maria Emília Franco Oliveira ${ }^{1}$ \\ Alexandre Arenales ${ }^{2}$ \\ Daniela Bernadete Rozza ${ }^{2}$ \\ Carlos Antonio Miranda Bomfim ${ }^{2}$ \\ Marion Burkhardt Koivisto ${ }^{2}$
}

\begin{abstract}
RESUMO
O objetivo deste relato é descrever os achados clínicos, histológicos e o tratamento cirúrgico de um caso de melanocitoma congênita. Esta neoplasia é considerada rara na espécie bovina, de classificação histológica variável e comportamento biológico difícil de ser previsto.
\end{abstract}

Palavra-chaves: melanócitos, melanocitoma, tumor congênito.

\section{PERIVULVAR BOVINE CONGENITAL MELANOCYTOMA}

\begin{abstract}
The objective of this report is to describe the clinical, histological and surgical treatment of a case diagnosed as congenital melanocytoma, located in perivulvar region in a half-breed cow (zebu).This neoplasia is considered rare in cattle, of variable histological classification and hard to predict biological behavior.
\end{abstract}

Key words: melanocytes, melanocytoma, congenital tumour.

\section{MELANOCITOMA PERIVULVAR CONGÉNITO EN BOVINO}

\section{RESUMEN}

El objetivo de este relato es describir lós hallazgos clínico, histológico de um tratamiento quirúrgico de un caso diagnosticado como melanocitoma congênito. Localizado en región perivulvar en una vaca mestiza (cebuina). Neoplasia considerada rara en especie bovina, classificación histológica variable y comportamiento biológico difícil de ser previsto.

Palabras claves: melanocito, melanocitoma, tumor congénito.

\section{INTRODUÇÃO}

Neoplasias melanocíticas cutâneas são oriundas dos melanócitos e classificadas como melanocitomas quando benignos e melanomas quando malignos (1). Na espécie bovina esta neoplasia tem sido relatada na região cutânea do tórax, abdômen, lombar e nos membros, como jarrete e metacarpo $(2,3)$, além de ocasionalmente ser encontrada nas regiões intraocular (4) e periauricular (5). O tipo congênito foi observado apenas em $1 \%$ dos casos notificados, mas compreendem $27 \%$ de todas as neoplasias de pele em bovinos (6).

Tumores em bezerros recém-nascidos ou jovens ( $>2$ meses de idade) são considerados raros e indicam uma provável natureza congênita, em que o fator genético ao invés do ambiental possa estar envolvido (6). A descrição de casos congênitos pode trazer dados 
relevantes para a literatura em relação ao efeito dessas neoplasias sobre a vida dos animais afetados, como risco de metástase, asciste, distocias ou outros achados clínicos que podem levar ao óbito (7). Além disso, o comportamento biológico e achados histopatológicos são considerados variáveis no melanocitoma e, que podem ser diferentes das lesões adquiridas na forma adulta comparado com casos congênitos. $(2,6,8)$.

Informações referentes às neoplasias em bovinos são extremamente válidas tanto para compreensão da etiopatogenia, tratamento e prognóstico, como também para a redução de perdas econômicas. A ocorrência de patologias como estas em animais destinados ao abate leva a condenação da carcaça e/ou vísceras por serem consideradas impróprias para o consumo, segundo a legislação ou ainda, em muitos casos, ser responsável pela indicação de eutanásia dos animais $(9,10)$.

Há certa carência de relatos de neoplasias em bovinos, possivelmente em virtude das descrições serem baseadas em peças de abatedouros. A ocorrência de melanocitomas na região perivulvar e de caráter congênito não foi relatada na literatura até o presente momento. Neste contexto, o objetivo deste relato é descrever os achados clínicos, cirúrgico e histopatológico de um caso de melanocitoma perivulvar congênito na espécie bovina, e compará-lo aos casos já descritos na literatura.

\section{RELATO DE CASO}

Foi atendido nas proximidades do município de Ivinhema, estado do Mato Grosso do Sul, uma vaca, mestiça (zebuína), criada em sistema extensivo, com aproximadamente 4 anos de idade. A fêmea apresentava nódulo pendunculoso perivulvar de crescimento lento, observado desde o nascimento, o qual ocorreu na mesma propriedade. No histórico genealógico verificou-se que a mãe deste animal era saudável e não apresentava nenhuma lesão semelhante. $\mathrm{O}$ animal com o nódulo já havia tido dois partos normais sem nenhuma complicação, apesar da grande massa perivulvar.

Ao exame clínico geral, o animal aparentava bom escore corporal, ativo e segundo histórico reprodutivo havia parido uma bezerra há dois anos por parto eutócico. No exame clínico específico, o nódulo localizado na região perivulvar esquerda media $20 \mathrm{~cm}$ x $20 \mathrm{~cm}$ x $8 \mathrm{~cm}$ e apresentava consistência firme, superfície enegrecida, ulcerada e que havia previamente sido tratada contra miíase (Figura1).

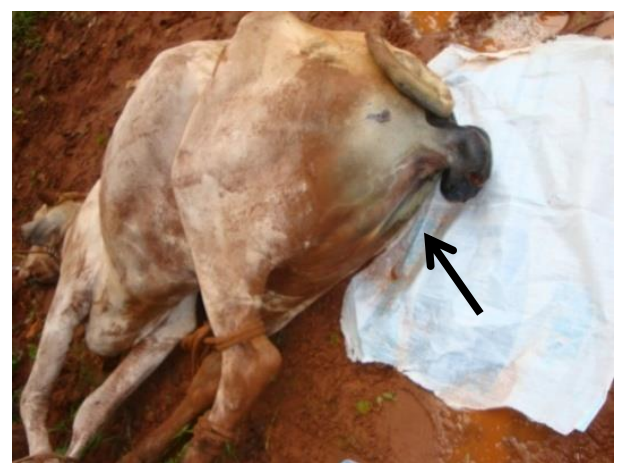

Figura 1. Animal em decúbito lateral direito com destaque (seta) ao nódulo enegrecido medindo de $20 \mathrm{~cm} \times 20 \mathrm{~cm} \times 8 \mathrm{~cm}$, de consistência firme, ulcerado e localizado na região perivulvar esquerda.

Diante da reincidência de miíases e pensando no bem-estar do animal, optou -se pela exerese do nódulo. Após sedação com xilazina $\left(0,3 \mathrm{mg} / \mathrm{kg} / \mathrm{IM} ;\right.$ Xilazin ${ }^{\circledR}$, cloridrato de xilazina, Syntec, Brasil) e bloqueio infiltrativo com lidocaína (Anestésico-L ${ }^{\circledR}$, cloridrato de lidocaína e epinefrina, Pearson, Brasil), foi realizada incisão elíptica na pele e tecido 
subcutâneo até exérese do tumor. A massa tumoral não estava aderida a musculatura o que facilitou a ressecção cirúrgica. No entanto, durante o procedimento observou-se intensa hemorragia, devido à presença de grandes vasos que irrigavam o tumor que foi contido por ligadura com fio monofilamentar não absorvível $(0.40 \mathrm{~mm})$.

Após ressecção cirúrgica da massa tumoral, verificou-se grande área de espaço morto $( \pm 15 \mathrm{~cm})$, porém ao realizar a divulsão do tecido subcutâneo remanescente foi possível aproximar as bordas da ferida cirúrgica sem grandes dificuldades. O tecido subcutâneo foi aproximado com padrão de sutura simples contínuo (Cushing) e pele com ponto simples separado (Wolf), utilizando fio monofilamentar não absorvível $(0.40 \mathrm{~mm})$. Foi instituída terapia parenteral com oxitetraciclina $\left(20 \mathrm{mg} / \mathrm{kg} / \mathrm{IM}\right.$; Terramicina ${ }^{\circledR L A}$, Pfizer, Brasil) três doses a cada 48 horas e flunexina meglumine $\left(1.1 \mathrm{mg} / \mathrm{kg} / \mathrm{IM}\right.$; Flunamine ${ }^{\circledR}$, Bayer, Brasil) por 2 dias a cada 24 horas.

A análise histopatológica revelou proliferação de alta densidade celular, nodular, expansiva e não encapsulada (Figura 2a), formada por múltiplos feixes sem direção definidos por células frouxamente agrupadas e entremeadas por estroma fibrovascular abundante (Fig. 2b). Individualmente as células mostraram citoplasma fusiforme, bem delimitado, de tamanho moderado e preenchido por quantidade abundante de grânulos enegrecidos de melanina; o núcleo mostrou-se central, pequeno e redondo com cromatina grosseiramente agregada, hipocromática e nucléolo central evidente. O pleomorfismo celular foi moderado a acentuado com baixo índice mitótico e ausência de invasão vascular. Na epiderme observou-se ausência de atividade juncional associado a uma estreita faixa de derme superior íntegra, caracterizando zona de Grenz (Fig. 2a), compatível com melanocitoma dérmico perivulvar.
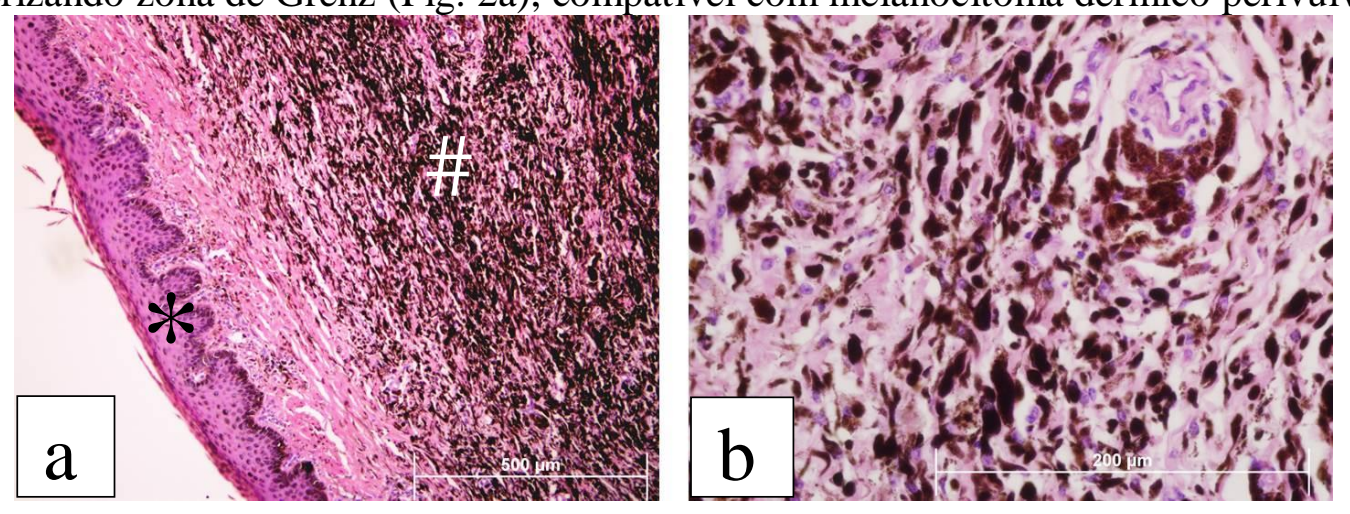

Figura 2. Corte histopatológico de melanocitoma dérmico perivular. a) proliferação nodular de alta densidade celular (\#); zona de Grenz (*) HE. 100x. b) células fusiformes com citoplasma preenchido por grânulos de melanina entre abudante estroma fibrovascular. Observe o pleomorfismo celular moderado a acentuado. HE. 400x.

\section{DISCUSSÃO}

Em bovinos, os melanocitomas cutâneos são mais frequentes em rebanhos de pelagem vermelha, cinza ou preta (7). Os animais acometidos não apresentam alterações grave do estado clínico geral, no entanto, há possibilidade do tecido neoplásico se tornarem grandes massas e ulcerarem predispondo à míiases; achado comum nas grandes neoplasias ulceradas e com longo tempo de evolução (>11 meses de idade) (8), como observado no presente caso.

A excisão cirúrgica de melanocitoma é sempre recomendada, considerada fácil e com baixos índices de recorrência independente da origem congênita ou adquirida (4,7). Porém, no presente caso, provavelmente devido ao longo tempo de evolução (4 anos), o grau de dificuldade da cirurgia foi maior, devido à formação de vasos sanguíneos calibrosos, presença abundante de estroma e consequentemente amplo espaço morto após a retirada da massa 
tumoral. No entanto, a escolha da remoção do tumor por meio de incisões em formato elípitico mostrou-se satisfatória, com prognóstico favorável, tendo em vista a boa cicatrização da ferida cirúrgica (sete dias) e a não ocorrência de complicação pós-operatória, tais como infecções ou pneumovagina, visto o fácil contato com material fecal ou pela perda da integridade dos lábios vulvares, respectivamente.

A aparência macroscópica do melanocitoma no presente caso se assemelha com os descritos na literatura: grande nódulo solitário, firme, enegrecido e ulcerado $(7,8)$. A coloração escura é resultado da deposição de melanina pelos melanócitos neoplásicos e considerado comum neste tipo de neoplasia, apesar dessa característica não ser excludente para o diagnóstico $(2,7)$.

Os melanocitomas dérmicos variam de células epitelióides e/ou fusiformes, com quantidade variável de melanina intra-citoplasmática, apresentam baixo índice mitótico e pleomorfismo; fatores estes utilizados como critério de distinção com melanomas $(1,6,7)$. Entretanto, estes achados devem ser utilizados com prudência, principalmente em lesões localizadas em junções mucocutâneas que tendem a ser mais agressivas, como descrito por Brito (8), ao relatarem um melanoma metastático na cavidade oral de uma vaca, com padrão histopatológico semelhante ao melanocitoma. Desta forma, uma observação criteriosa dos vasos linfáticos regionais e sanguíneos, principais vias de metástase (2) contribui para o diagnóstico diferencial. O predomínio de células fusiformes, núcleo pequeno, baixo índice mitótico e ausência de invasão vascular foram características suficientes para definir este caso de localização atípica como benigno.

O fator etiológico para o desenvolvimento de tumores congênitos e do melanocitoma ainda não está completamente esclarecido. Acredita-se que são de origem multifatorial, e uma possível via patogenética tem sido levada em consideração, em que estas neoplasias desenvolvem durante estágios embrionários ou imediatamente após o nascimento (7). Fatores hereditários foram associados com o desenvolvimento de melanomas em suínos recémnascidos da raça Sinclair, pais com melanomas podem aumentar a incidência em 54\% em sua prole nessa espécie, o que indica a existência de um fator transmissível pelos pais para odesencadeamento desta neoplasia (9). Até o momento não há estudos em bovinos avaliando a relação do fator hereditário para o desenvolvimento da lesão. Infelizmente no presente caso essa teoria não foi possível de ser averiguada, devido à falta de informação referente ao histórico de todos os ascendentes na genealogia do animal, mas não pode ser descartado como possível fator etiológico envolvido.

Neoplasias melanocíticas podem desenvolver-se em diversos locais como já citados $(2,4,6,7)$, porém no trato genital de bovinos são consideradas incomuns (10). Segundo Yeruham (10), o carcinoma de células escamosas na vulva são os mais prevalentes e a exposição solar é um dos potenciais agentes carcinogênicos. Fator este que também é mencionado em casos de melanomas, quando a exposição aos raios UVA e UVB podem induzir mutações secundárias em tecidos predispostos (2). Não é possível afirmar que fatores ambientais, como o anteriormente mencionado, foram os responsáveis pelo desenvolvimento inicial do tumor, por se tratar de uma neoplasia congênita. No entanto, supõem-se que a alta exposição solar e o tipo de sistema de criação (extensivo), em que geralmente há poucas áreas de sombreamento, também possa ter contribuído para o crescimento do tecido neoplásico.

\section{CONCLUSÃO}

No caso relatado, o melanocitoma congênito perivulvar apresentou características clínicas e histológicas semelhantes aos casos descritos na literatura apesar da localização atípica e pelo longo tempo de evolução. O tratamento cirúrgico foi considerado satisfatório pela rápida recuperação, baixo custo e ausência de recorrência após cinco meses do pós- 
operatório. Apesar do prognóstico favorável e baixo risco de metástase é recomendado o descarte do animal devido a real possibilidade do fator hereditário estar associado a etiologia desta neoplasia.

\section{REFERÊNCIAS}

1. Conceição LG, Santos RL. Sistema tegumentar. In: Santos RL, Alessi AC. Patologia veterinária. São Paulo: Roca; 2010. p.423-523.

2. Foley GL, Valentine BA, Kincaid AL. Congenital and acquired melanocytomas (benign melanomas) in eighteen young horses. Vet Pathol. 1991;28:362-9.

3. Schuh JCL. Congenital intraocular melanoma in a calf. J Comp Pathol. 1989;101:113-6.

4. Pochini LR, Alessi AC, Marques LC, Valadão CAA, Castro MB. Melanocitoma dérmico fibroso em bezerra. Arq Bras Med Vet Zootec. 1998;50:461-4.

5. Misdorp W. Congenital tumours and tumour-like lesions in domestic animals. 1 Cattle: a review. Vet Q. 2002;24:1-11.

6. Goldschmidt MH, Hendrick MJ. Tumors of the skin and soft tissues. In: Meuten DJ. Tumors in domestic animals. Iowa: Ames; 2002. p.44-117.

7. Miller MA, Weaver AD, Stogsdill PL, Fischer JR, Kreeger JM, Nelson SL, et al. Cutaneous melanocytoms in 10 young cattle. Vet Pathol. 1995;32:479-84.

8. Brito MF, França TN, Jabour FF, Seixas JN, Andrade GB, Oliveira LI, et al. Metastasizing oral melanoma in a cow. Cienc Rural. 2009;39:1248-52.

9. Teixeira C, Pires I, Ferreira S, Vierira-Pinto M. Lesões melanocíticas em suínos abatidos para consumo. Arq Bras Med Vet Zootec. 2013;65:783-91.

10. Yeruham I, Perl S, Orgad U, Yakobson B. Tumours of the vulva and vagina in cattle: a 10 year survey. Vet J. 1999;158:237-9. 